\title{
Autopsy in suspected COVID-19 cases
}

\author{
Brian Hanley (1) ,' Sebastian B Lucas, ${ }^{2}$ Esther Youd, ${ }^{3}$ Benjamin Swift, ${ }^{4}$ \\ Michael Osborn (1) ${ }^{1}$
}

'Department of Cellular Pathology, Imperial College London NHS Trust, London, UK ${ }^{2}$ Department of Histopathology, GKT, Medical school in London, London, UK ${ }^{3}$ Department of Histopathology, Cwm Taf Morgannwg Health Board, Llantrisant, UK ${ }^{4}$ Forensic Pathology Services, Oxon, UK

\section{Correspondence to}

Dr Brian Hanley, Cellular Pathology, Imperial College London NHS Trust, London, UK brian.hanley1@nhs.net

Received 9 March 2020 Accepted 11 March 2020 Published Online First 20 March 2020

\section{Check for updates}

(C) Author(s) (or their employer(s)) 2020. No commercial re-use. See rights and permissions. Published by BMJ.

To cite: Hanley B, Lucas SB, Youd $E_{\text {, et al. J Clin Pathol }}$ 2020;73:239-242.

\begin{abstract}
The severe acute respiratory syndrome (SARS)-

coronavirus-2 (CoV-2) outbreak in Wuhan, China has now spread to many countries across the world including the UK with an increasing death toll. This will inevitably lead to an increase in the number of suspected coronavirus disease 2019 (COVID-19)-related deaths at autopsy. The Royal College of Pathologists has responded to this concern with the release of a briefing on autopsy practice relating to COVID-19. The following article is a summary and interpretation of these guidelines. It includes a description of hazard group 3 organisms, the category to which SARSCoV-2 has been assigned, a brief description of what is currently known about the pathological and autopsy findings in COVID-19, a summary of the recommendations for conducting autopsies in suspected COVID-19 cases and the techniques for making the diagnosis at autopsy. It concludes by considering the clinicopathological correlation and notification of such cases.
\end{abstract}

\section{INTRODUCTION}

The coronavirus family comprises several zoonotic viruses that cause serious human diseases including Middle East respiratory syndrome (MERS) and severe acute respiratory syndrome (SARS). ${ }^{1}$ In late 2019, a new coronavirus outbreak due to SARS-coronavirus-2 (SARS-CoV-2) began in Wuhan, China, which causes an illness in humans designated as coronavirus disease 2019 (COVID-19) by the WHO. ${ }^{2}$ COVID-19 pathobiology remains incompletely understood and significant efforts are underway to study it worldwide.

SARS-CoV-2 continues to spread as the number of deaths continue to increase. ${ }^{3}$ The mode of transmission of the virus is thought to be largely by inhalation of respiratory droplets although acquisition via the skin surface is another possibility. ${ }^{4}$ Fever is usually the first symptom with subsequent development of respiratory symptoms. ${ }^{5}{ }^{6}$ Most patients with COVID-19 have a mild disease course; however, approximately $20 \%$ develop severe disease with high mortality rate and is associated with older age and immunosuppression. $^{56}$

In February 2020, the Royal College of Pathologists (RCPath) released guidance on postmortem examinations for mortuary workers in suspected COVID-19 cases. ${ }^{4}$ This article summarises those guidelines. It is based on our current understanding of COVID-19 in early March 2020 and may change as more information becomes available.

\section{HAZARD GROUP CATEGORISATION OF COVID-19}

In the UK, pathogens are categorised according to their risk to humans by the Advisory Committee on Dangerous Pathogens (ACDP) within the
Health and Safety Executive. ${ }^{7}$ ACDP guidance is largely aimed towards staff in clinical and researchrelated microbiology laboratories, however given the potential risk to the health of mortuary staff, autopsy practice has been adapted to reflect the risk of transmission of infectious pathogens during and after the postmortem examination. ${ }^{8}$ These hazard groups (HG1-4) are assigned according to the risk of human infection, the likelihood spread and access to treatment or prophylaxis (see table 1). Control of substances hazardous to health $(\mathrm{COSHH})$ defines four containment levels for working with these, which correspond directly to the organism's hazard group (ie, containment level 3 should be used for hazard group 3 organisms).

The SARS-related and MERS-related coronaviruses are both considered HG3 pathogens, while most other Coronavirinae are HG2.' SARS-CoV-2 has recently been categorised as a HG3 organism. ${ }^{49}$ Other viruses within HG3 include rabies, poliovirus, dengue virus, hepatitis virus $\mathrm{B}, \mathrm{C}, \mathrm{D}$ and $\mathrm{E}$, and HIV 1 and 2 among others. ${ }^{4}$ Certain HG3 organisms (eg, hepatitis B, C, $\mathrm{D}$ and $\mathrm{E}$ virus) may be used at containment conditions less than those outlined by COSHH for HG3 organisms; however, SARS-CoV-2 is not on this list. ${ }^{7}$ Once appropriate precautions are in place, the risk to mortuary workers dealing with these HG3 organisms are slight, and a well-staffed mortuary with experienced personnel should be capable of handling cases with any of these HG3 pathogens.

\section{RISK REDUCTION DURING POSTMORTEM EXAMINATION IN HG3 ORGANISMS}

In general, conducting an autopsy on a patient with a suspected HG3 organisms requires four areas of attention: risk assessment, understanding of the pathology that may be found, universal standard precautions and any standard operating procedures for specific HG3 pathogens. The effective utilisation of universal precautions mitigates against inaccurate or incomplete information used in the risk assessment on an individual case basis.

Mortuary workers performing autopsies have a duty outlined by COSHH to perform risk assessments in every postmortem examination for the safety of themselves and their colleagues. Before the time of the autopsy, this may include a review of the clinical history on the consent form or coroner request form, information attained from the patient's doctors, laboratory records and hospital infection control and external examination findings.

It must be stressed at this point that if the death is considered to be due to a confirmed COVID-19 
Table 1 ACDP hazard group definitions: table adapted from ref 7

\begin{tabular}{ll}
\hline ACDP hazard group definitions \\
\hline Group 1 & $\begin{array}{l}\text { Not likely to lead to disease in humans. } \\
\text { Group } 2\end{array}$ \\
$\begin{array}{l}\text { May lead to human disease and risk to employees but not likely to } \\
\text { spread to other humans. Prophylaxis and/or treatment are generally } \\
\text { accessible. }\end{array}$ \\
Group 3 & $\begin{array}{l}\text { May lead to severe human disease and can be a significant risk to } \\
\text { employees. It can spread to other humans. Prophylaxis and/or treatment } \\
\text { are generally accessible. }\end{array}$ \\
Group 4 & $\begin{array}{l}\text { Leads to severe human disease and poses a significant risk to } \\
\text { employees. It is likely to spread to other humans. No prophylaxis and/or } \\
\text { treatment are generally accessible. }\end{array}$ \\
\hline
\end{tabular}

ACDP, Advisory Committee on Dangerous Pathogens.

infection, an autopsy is unlikely to be necessary and a Medical Certificate of Cause of Death should be given. However, if the infection is involved in a forensic case, then legal duty impels the proper performance of a full appropriate autopsy. The issue of whether a person dies with or from COVID-19 infection may not always be straightforward, and ongoing epidemiology and available investigation data may shed light on this.

\section{PATHOLOGICAL FINDINGS IN COVID-19}

Information regarding the pathological findings in COVID-19 is limited, although several case reports have been published in recent weeks. ${ }^{10} 11$

Clinical features: Public Health England (PHE) has outlined criteria to assess possibility of COVID-19 infection in patients. ${ }^{12}$ These criteria are the same when the patient is deceased with the exception that the timelines given in the guidance refer to the time prior death or onset of relevant symptoms before death where known.

If it is considered that COVID-19 may have been related to death by these criteria, the choice of either to perform a full postmortem or an examination is limited only to retrieving the samples required to verify COVID-19 infection. This decision must be made according to the individual case and should include the requirements of the coroner or any pertinent individuals. A staged postmortem may also be considered. This involves taking only diagnostic samples initially and later considering or a more complete autopsy after the results of these diagnostic tests are available. This staged technique is recommended if possible.

Macroscopic features: the macroscopic features of COVID-19 are likely to be in the chest and may include pleurisy, pericarditis, lung consolidation and pulmonary oedema. Lung weight may be increased above normal. It should be noted a secondary infection may be superimposed on the viral infection that can lead to purulent inflammation more typical of bacterial infection. ${ }^{4}$

Microscopic findings: a recent article described the early histopathological features in COVID-19 in two patients who underwent surgical resections for lung adenocarcinoma but were later discovered to have had COVID-19 at the time of the operation. ${ }^{11}$ The findings were non-specific and included oedema, pneumocyte hyperplasia, focal inflammation and multinucleated giant cell formation while no hyaline membranes were seen. Given that these patients were asymptomatic with respect to COVID-19 at the time of the operation, these are likely to reflect only early changes of acute lung injury in the infection. ${ }^{11}$ In another case, a 50-year-old man died from severe COVID-19 infection and more marked histopathological findings were noted. ${ }^{10}$ Samples were taken by postmortem biopsy, and a description of the gross postmortem findings is not given, although multiple ground glass opacities were noted on chest X-ray. The microscopic findings included diffuse alveolar damage with exudates. ${ }^{10}$ The inflammation was predominantly lymphocytic, and multinucleated giant cells were seen alongside large atypical pneumocytes, although no definitive viral inclusions were noted. Microvesicular steatosis with mild inflammation was noted in the liver, although it was unclear whether this was related to the virus or iatrogenic. The features are very similar to those seen in SARS and MERS-coronavirus infections. ${ }^{13} 14$

\section{MORTUARY FACTORS}

Adequate ventilation is need where HG3 autopsies are being performed with enough separation from the rest of the mortuary. Either whole room ventilation or down-drafts at the work stations are acceptable. ${ }^{15}$ Any electric bone saws used should have a vacuum that isolates aerosolised particles. It is preferable to have an isolated high-risk facility for performing HG3 autopsies, although this is not compulsory. ${ }^{8}$ All essential equipment should be brought at the start of the postmortem examination (eg, sample receptacles, culture bottles and so on) to eliminate the need to leave and re-enter the workspace. Further information may be found in the appropriate National Health Service guidance documents. ${ }^{16}$

The team available for these high-risk, postmortem examinations best includes the pathologist, the anatomic pathology technician (APT) and a third circulator. The presence of a circulator is beneficial but not essential. ${ }^{8}$ Suitably experienced autopsy pathology trainees (as assessed by senior staff) may be involved in HG3 autopsies with adequate supervision. No specific infection risk to pregnant trainees has been identified; however, they may decide not to undertake autopsy work, and this should be discussed with the deanery.

\section{Performance of the autopsy in HG3 infections}

Several techniques undertaken at autopsy can reduce the risks encountered by HG3 infections. Personnel must be adequately trained. For APTs, this exposure should be in line with their curriculum and standardised training under the Royal Society for Public Health. For pathology trainees, this is at the discretion of senior staff. Sharps injuries can be reduced by minimising sharps in the workspace, using round-ended scissors, bluntended PM40 blades and having only a single operator working in the body cavity at a time. ${ }^{4}$ Fresh organs should be sliced while being stabilised with a sponge on a solid surface. Needles should be placed in sharps bins and never resheathed.

Personal protective equipment (PPE) is vital. Certain PPE is universally used in postmortem examinations (box 1); however, the typical surgical masks are not considered sufficient protection. Valved fold flat and moulded protection masks are over 95\% effective and are suitable for use in anticipated COVID-19 cases. ${ }^{4}$ Whole-body suits with individual respirators seem to provide almost complete protection, although these are impractical and not necessary. ${ }^{15}$

A staged postmortem is recommended by RCPath. ${ }^{4}$ Where a more detailed examination is necessary, a limited postmortem may be considered. In widespread infections, a minimally invasive postmortem examination can be performed to provide necessary fluid and tissue samples; ${ }^{17}$ however, regional or localised infections may be difficult to identify with this technique alone, although they may be improved by combination with postmortem imaging. 
Box 1 List of minimum personal protective equipment (PPE) in suspected coronavirus disease 2019 (COVID-19) cases

Universal PPE
Surgical scrubs.
Scrub hat.
Clear face visor.
Waterproof gown to cover whole body and forearms
(typically a surgical gown).
Plastic apron.
Rubber boots with metal toecaps.
Protective kevlar or neoprene cut-resistant under-gloves.
Adingle use disposable non-latex gloves.
cases
Fold flat and moulded protection mask or whole-body suit.

Postmortem CT (PMCT) examination: histopathologists with local agreements regarding access to scanning facilities may contemplate PMCT to demonstrate significant pulmonary findings or identify causes of death in a case with incidental SARS-CoV-2 infection. A recently multicentre study $(n=101)$ showed ground-glass lung opacities in $86 \%$ of cases, or mixed ground-glass and consolidation in $64 \%$ of patients examined. ${ }^{18}$ Vascular enlargement and traction bronchiectasis are also described (71\% and 53\%, respectively). The changes were more likely to be bilateral, peripherally distributed and involving the lower lobes. The decision to undertake native PMCT or ventilated PMCT would be for the reporting radiologist following consultation: use of an existing clinical airway, or creation of a tracheostomy postmortem, would provide access for ventilation and potentially lower respiratory tract sampling.

\section{Diagnosis of COVID-19}

The samples required to diagnose COVID-19 at autopsy are the same as those required during life. They include a $5 \mathrm{~mL}$ sample of plain blood (no additive) for serology, upper aerodigestive tract swabs (nose and throat) and lower respiratory tract samples (bronchoalveolar lavage or sputum). ${ }^{19}$ For full and up-to-date details on how to submit these samples, one should follow the links in the references. ${ }^{19}$ It should be noted that the submission of each sample requires a specific E28 form. The specific advice from PHE is that one swab should be used for the upper aerodigestive tract and another swab for the lower respiratory tract. ${ }^{4}$

RCPath recommends that standard samples, such as respiratory tract swabs and tissue samples, should also be sent to local microbiology departments simultaneously to detect pathogens in the differential diagnosis. Where possible, a complete set of tissue histology is also recommended along with other specific investigations as outlined on a case-by-case basis. Standard formalinfixation inactivates known coronaviruses and SARS-CoV-2 is believed to be similarly affected. ${ }^{20}$

Ready-to-use swabs can collect respiratory tract samples. Blood, urine and cerebrospinal fluid samples, where deemed appropriate, should be taken prior to opening the body cavity and under as sterile conditions as possible to reduce contamination. This may be achieved using alcohol-containing disinfectant to clean the skin. Blood cultures should be taken preferentially from the subclavian vein, jugular vein or left ventricle to reduce contamination from the bowel.

\section{CONCLUSION}

We have outlined the hazard group categorisation, pathological features and approach to the autopsy in suspected COVID-19 cases to aid mortuary workers. If on clinicopathological correlation, COVID-19 is deemed to be primary cause of death, then it should be given at the last line of part 1 in the Office of National Statistics format. If there is another primary cause of death and COVID-19 is considered to be contributory, then it can be put in part 2. Finally, it is worthwhile to notify PHE of any cases where COVID-19 is confirmed, although this should also be done by the laboratory that made the diagnosis.

Correction notice This article has been corrected since it appeared Online First. The abstract has been replaced, and a new sentence and reference added "Standard formalin-fixation inactivates known coronaviruses and SARS-CoV-2 is believed to be similarly affected[20]". Several minor text changes have been made throughout.

\section{Handling editor Tahir S Pillay.}

Contributors $\mathrm{BH}$ designed and planned the manuscript performed the literature review, wrote the paper and collaborated with other authors in review. SBL, EY and $\mathrm{BS}$ reviewed manuscript drafts and contributed several paragraphs. MO designed and planned the manuscript and was involved in review of drafts along with collaborating between coauthors for multidisciplinary input.

Funding The authors have not declared a specific grant for this research from any funding agency in the public, commercial or not-for-profit sectors.

Competing interests None declared.

\section{Patient consent for publication Not required.}

Provenance and peer review Commissioned; internally peer reviewed.

This article is made freely available for use in accordance with BMJ's website terms and conditions for the duration of the covid-19 pandemic or until otherwise determined by BMJ. You may use, download and print the article for any lawful, non-commercial purpose (including text and data mining) provided that all copyright notices and trade marks are retained.

\section{ORCID iDs}

Brian Hanley http://orcid.org/0000-0003-4130-920X

Michael Osborn http://orcid.org/0000-0001-6290-4839

\section{REFERENCES}

1 Holmes KV. Sars-Associated coronavirus. N Engl J Med 2003;348:1948-51.

2 World Health Organization. Director General's remarks at the media briefing on 2019-nCoV on 11 February 2020. secondary director General's remarks at the media briefing on 2019-nCoV on 11 February 2020, 2020. Available: https://www.who.int/ dg/speeches/detail/who-director-general-s-remarks-at-the-media-briefing-on-2019ncov-on-11-february-2020

3 European Centre for Disease Prevention and Control. Threats and outbreaks: COVID-19 secondary threats and outbreaks: COVID-19, 2020. Available: https://www. ecdc.europa.eu/en/novel-coronavirus-china

4 Osborn M, Lucas S, Stewart R, et al. Autopsy practice relating to possible cases of COVID-19 (2019-nCov, novel coronavirus from China 2019/2020) secondary autopsy practice relating to possible cases of COVID-19 (2019-nCov, novel coronavirus from China 2019/2020), 2020. Available: https://www.rcpath.org/uploads/assets/ d5e28baf-5789-4b0f-acecfe370eee6223/fe8fa85a-f004-4a0c-81ee4b2b9cd12cbf/ Briefing-on-COVID-19-autopsy-Feb-2020.pdf

5 Huang C, Wang Y, Li X, et al. Clinical features of patients infected with 2019 novel coronavirus in Wuhan, China. The Lancet 2020;395:497-506.

6 Wang D, Hu B, Hu C, et al. Clinical characteristics of 138 hospitalized patients with 2019 novel coronavirus-infected pneumonia in Wuhan, China. JAMA 2020.

7 Health and Safety Executive Advisory Committee on Dangerous Pathogens. The Approved list of biological agents. secondary the Approved list of biological agents. Available: www.hse.gov.uk/pubns/misc208.pdf

8 Health and Safety Executive. Safe working and the prevention of infection in the mortuary and post-mortem room. secondary safe working and the prevention of infection in the mortuary and post-mortem room, 2018. Available: https://www. rcpath.org/uploads/assets/d5e28baf-5789-4b0f-acecfe370eee6223/fe8fa85a-f0044a0c-81ee4b2b9cd12cbf/Briefing-on-COVID-19-autopsy-Feb-2020.pdf

9 Public Health England. COVID-19: safe handling and processing for laboratories secondary COVID-19: safe handling and processing for laboratories, 2020. Available: https://www.gov.uk/government/publications/wuhan-novel-coronavirus-guidance-for- 


\section{Best practice}

clinical-diagnostic-laboratories/wuhan-novel-coronavirus-handling-and-processing-oflaboratory-specimens

10 Xu Z, Shi L, Wang Y, et al. Pathological findings of COVID-19 associated with acute respiratory distress syndrome. The Lancet respiratory medicine.

11 Tian S, Hu W, Niu L, et al. Pulmonary pathology of early phase 2019 novel coronavirus (COVID-19) pneumonia in two patients with lung cancer. J Thorac Oncol 2020:S15560864(20)30132-5.

12 Public Health England. COVID-19: investigation and initial clinical management of possible cases. secondary COVID-19: investigation and initial clinical management of possible cases, 2020. Available: https://www.gov.uk/government/publications/wuhannovel-coronavirus-initial-investigation-of-possible-cases/investigation-and-initialclinical-management-of-possible-cases-of-wuhan-novel-coronavirus-wn-cov-infection

13 Ding $\mathrm{Y}$, Wang $\mathrm{H}$, Shen $\mathrm{H}$, et al. The clinical pathology of severe acute respiratory syndrome (SARS): a report from China. J Pathol 2003;200:282-9.

$14 \mathrm{Ng} \mathrm{DL}$, Al Hosani F, Keating MK, et al. Clinicopathologic, immunohistochemical, and ultrastructural findings of a fatal case of middle East respiratory syndrome coronavirus infection in the United Arab Emirates, April 2014. Am J Pathol 2016;186:652-8.
15 Lucas S. Autopsies on people with high-risk infections. In: The hospital autopsy: a manual of fundamental autopsy practice. 3rd edition. London, UK: Hodder Arnold, 2010.

16 NBS T. Hbn 20 facilities for mortuary and post-mortem room services (3rd edition). secondary HbN 20 facilities for mortuary and post-mortem room services (3rd edition), 2005. Available: www.thenbs.com/PublicationIndex/documents/details?Pub=NHS\& DoclD $=275892$

17 Castillo P, Martínez MJ, Ussene E, et al. Validity of a minimally invasive autopsy for cause of death determination in adults in Mozambique: an observational study. PLoS Med 2016;13:e1002171.

18 Zhao W, Zhong Z, Xie X, et al. Relation between chest CT findings and clinical conditions of coronavirus disease (COVID-19) pneumonia: a multicenter study. AJR Am J Roentgenol 2020:1-6.

19 Public Health England. COVID-19: guidance for sampling and for diagnostic laboratories secondary COVID-19: guidance for sampling and for diagnostic laboratories, 2020. Available: https://www.gov.uk/government/publications/wuhannovel-coronavirus-guidance-for-clinical-diagnostic-laboratories

20 Henwood AF. Coronavirus disinfection in histopathology. J Histotechnol 2020;16:1-3. 